\title{
HIGHER EDUCATION IN BALKAN REGION AND ITS CONTRIBUTION TO THE EARTH OBSERVATION
}

\author{
A. Lisec ${ }^{\mathrm{a}, *}$, M. Kosmatin Fras ${ }^{\mathrm{a}}$ \\ ${ }^{a}$ UNI Ljubljana, Faculty of Civil and Geodetic Engineering, Jamova c. 2, 1000 Ljubljana, Slovenia - (anka.lisec, \\ mojca.kosmatin-fras)@fgg.uni-lj.si
}

Commission VI, WG VI/5

KEY WORDS: education, developing countries, research, environment, databases, resources

\begin{abstract}
:
The needs for spatial data as well as techniques of Earth Observation are changing, and new professional areas are developing very rapidly. In addition, scientific work and its connection with the teaching process have influenced the introduction of new cognitions into the higher education programs in general. Considering these facts, in the period shorter than one decade, the higher education institutions in the Balkan region, which have study programs in the fields of spatial data acquisition, analysis and spatial decisions, have made significant changes of the curricula. In our research, we have analyzed the current higher education programs in the Balkan region having focused on curricula related to the Earth Observation. Due to historical reasons, these curricula have its roots in surveying study programs in the most Balkan countries. The competences of classical surveying higher educational programs have been changing and nowadays include the wider area of spatial data acquisition, geoinformatics. In parallel, we present the current Earth Observation activities in the selected countries from the Balkan region. Based on the results of our research in the framework of the European program Observe, which aims to establish a new Balkan Earth Observation (EO) community of multilevel stakeholders that will make use of state of the art technological developments, products and knowhow from the existing European EO community and industry, we estimate the contribution of advanced higher educational programs to the Earth Observation activities in the selected countries.
\end{abstract}

\section{INTRODUCTION}

\subsection{SDI and EO data at the regional level}

"Technology has provided humankind with the means to monitor the Earth and its atmosphere in novel ways: remote sensing satellites have identified holes in the stratospheric ozone layer; atmospheric observatories atop Mauna Loa on the Island of Hawaii record the accumulation of carbon dioxide, sulphur dioxide and other pollutants. With these technologies, we have become cognizant of goods (and bads) of a global and regional nature”, are well known Sandler's words (Sandler, 1998). The emergence into our consciousness of transnational and global phenomena, e.g. degradation of the global environment, loss of biodiversity, natural disasters, has initiated the debate of how to reform the traditional, country-focused system of international development cooperation that has evolved over the past 50 years (see Georgiadou and Groot, 2002). In each of these instances, activities in one country spill over political borders, thus jeopardising the well-being of people in other countries.

As the consequence, a large awareness has been developed with respect to the strategic role of spatial data infrastructure (SDI) and Earth Observation (EO) systems at the regional and global levels in the last decade. The use of digital geospatial data, including the EO activities, could not be limited to the political (state) borders. Advanced use of those data is tightly connected with the quality and connectivity of data. Seamless integration of geospatial data from different sources (countries) and establishment of common patterns of objects in space mean perfect infrastructure of geospatial data, which is a condition for their advanced and efficient usage. To ensure that the spatial data infrastructures are compatible and usable in a transboundary context, the common implementing rules have to be adopted in a number of specific areas, including metadata, data specifications, network services, data and service sharing etc. (see for example The INSPIRE Directive: European Parliament and Council, 2007).

Unfortunately, the need for capacity building initiatives to be developed in parallel to the processes of SDI and EO activities is often underestimated. This is partly due to the confusion that exists about the meaning of capacity building itself. With this mind the following section of this paper considers the nature of capacity building in the EO field in the selected countries from the Balkan region, and is focused on the higher education as an important step towards the capacity building.

\subsection{Building EO capacity}

For the "capacity building" the wide variety of interpretations of the term could be found. In general, these include human resource development, organisational strengthening, and institutional strengthening (Kufoniyi et al., 2005). Nevertheless to some people it means essentially the training of technicians and managers although this definition is often extended to include the education of politicians and the general public outside the professional field. It is necessary to take a much broader view of capacity building.

\footnotetext{
* Corresponding author.
} 
According to the European report on GI Capacity Building in the EU Accession Period (GINIE, 2003), the "Geographic Information (GI) Capacity Building is the collective set of activities and processes that operate within a given society to deliver the correct balance of all necessary resources that ensure geographic information is available such that it meets the needs and demands of the given society in a sustainable way." If the term "geographic information" is replaced by "Earth Observation" this can be seen as a useful definition of some of the key strategic capacity building tasks involved in EO activities. The EO capacity building concerns for example the provision and raising of resources, especially a skilled workforce, data, technology and finance; building and empowering human networks by developing professional societies and their communication to support the transfer and dissemination of experience and good practice through out society; undertaking research, development and education and increasing knowledge transfer into practice; development of EO issues and affairs into institutional frameworks (such as legal, political) etc. This article focuses on EO capacity building in the context of the higher educational programmes in the selected Balkan countries, which have been included in the study of the European project OBSERVE (Observe, 2012).

\subsection{Balkan countries}

The word "Balkan" means a mountain chain. It is the name of a $600 \mathrm{~km}$-long mountain range in the central part of the peninsula extending from Serbia across Bulgaria to the Black Sea. In geographical terms, the Balkans ends in the north at the banks of the Danube and Sava rivers and on the slopes of the Alps, while its coasts in the south are lapped by the waves of the Adriatic, Ionian, Aegean and Black Seas. The territories of some countries fit totally within this area (Albania, Bulgaria, Bosnia and Herzegovina, Greece, Kosovo, Macedonia and Montenegro), while others have larger, smaller and symbolic shares (Croatia, Romania, Serbia, Slovenia and Turkey, and a small slice of land around Trieste in Italy), or they only touch its borders (Moldova) (Zgaga, 2011).

Definitions seem clear in geography textbooks, yet it is not easy to outline the region in cultural and political terms. Mutually comprehensible as well as incomprehensible languages are spoken, various scripts are used in writing and various religions are practised. Indeed, a purely geographic definition does not help much when discussing the region's politics and culture in general, or education in particular. The Western Balkans is today usually understood to include Albania and the former Yugoslavia, but not Slovenia. With Albania as an exception, the remaining countries of the Western Balkans shared a considerable part of $20^{\text {th }}$-century political history and the heritage of a common state, Yugoslavia, which was quite decentralized and after the mid-1960s it was more connected to the West, than to the East. Albania to the south-west side of the peninsula was (self-)isolated up until the 1990s. Looking at the Balkans in a broader framework, Bulgaria and Romania belonged to the Soviet bloc, while Moldova was an integral part of the Union of Soviet Socialist Republics. To the south of the Balkans, Greece was, politically speaking, the frontier to the West. It is not difficult to realize that such diverse contexts have also influenced the huge diversity seen in the region's higher education systems (Zgaga, 2011).

In late 1998 a conference was organized in Graz (Austria) on European Educational Co-operation for Peace, Stability and Democracy, which had a huge impact on educational reconstruction in the Western Balkans. This was the beginning of the so-called Graz Process. The Graz Process evolved into the Enhanced Graz Process (EGP), encompassing a number of governmental, non-governmental and international organizations. In the following years, it was the main supporter of the region's educational reconstruction, linking up with education trends in other European countries and promoting regional cooperation and networking as instruments for wider participation in international initiatives (Zgaga, 2011).

Alongside launching the Enhanced Graz Process, 29 European ministers signed the Bologna Declaration (1999), thus initiating a process aimed at constructing the European Higher Education Area (EHEA) until 2010. Its introductory part stresses that a "Europe of knowledge" is an irreplaceable factor of social and human growth as it fosters European citizenship, empowers citizens with the necessary competencies for working together, and with an awareness of shared values and belonging to a common social and cultural space. Bulgaria, Romania and Slovenia, as EU associated countries, were among the 29 signatory states to the Declaration. Croatia signed the Declaration in 2001 and the remaining five countries signed in 2003. Large parts of the Western Balkans needed serious reconstruction of the whole tertiary education system before entering the Bologna Process and this task was addressed within the framework of the EGP helping with the 'Bologna' agenda. Several common priorities were identified, including the need for new legislation and reform of university governance; the development of quality assurance mechanisms; the introduction of the European Credit Transfer and Accumulation System (ECTS); curriculum renewal; democratic and ethical standards, recognition of multi-ethnicity, etc. (Higher Education in Europe, 2003).

In spring 2010 the Bologna Process crossed the finish line, as defined in 1999. Yet in the Leuven Communiqué (2009) ministers self-critically noted that "not all the objectives have been completely achieved", and that proper implementation requires "an increased momentum and commitment beyond 2010". However, all countries of the EHEA have not been in an equal position in terms of modernizing their higher education systems. The countries of the Western Balkans joined the Process later than other countries, and it should not be a surprise to learn that various criticisms of the Bologna reforms have been often heard there in the last year or two. The good news is that ambitious projects at a departmental level are growing. The modernization of teaching and learning is really coming to the fore. Often it is connected to implementation of tools and strategies recommended by the Bologna Process, such as the credit system, student workload, learner-centred approaches, etc. (Zgaga, 2011).

\section{EO ACTIVITIES IN THE BALKAN REGION}

Balkan countries do not have a coherent and continuous approach towards the challenge of implementing integrated Earth Observation (EO) applications in environmental monitoring and management. The defect in the implementation of EO applications and their use in the environmental decision making are manifested through the limited synergies among national and regional institutions, the lack of substantial infrastructure, ineffective technological means, discontinuous record of participation to international organizations and committees (Observe, 2012). 
The increasing importance of a common approach towards effective environmental monitoring practices, for the benefit of the societal web of the broader Balkan region, calls for immediate action, setting as a starting point the built up of regional institutional capacity and spillage of technology transfer. For this reasons, the national reports for the selected countries in the Balkan area (Albania, Bosnia and Herzegovina - BiH, Bulgaria, Croatia, Former Yugoslav Republic of Macedonia - FYRoM, Greece, Serbia, Slovenia and Turkey) have been prepared in the framework of the European project OBSERVE, where a special attention has been given also to the higher educational programs covering the EO activities. The aim of the OBSERVE project is to collect and compile all the necessary information for delivering an integrated analysis on the current status of EO activities and networks in the Balkan area regarding environmental monitoring, the potential benefit from the full exploitation of an integrated capacity development strategy and the prospect of establishing a relevant permanent EO Community in the broader region.

\subsection{The state of the art in the selected Balkan countries}

Spatial data have a long history of use in support of decision making. This is true also for the Balkan countries which have a long tradition in mapping and cadastral evidences. With development of new technologies for spatial data acquisition and management, the importance of spatial data for the society is higher than it has ever been. Traditional maps have been replaced by digital spatial data. However, the new technology has brought new challenges in the fields of spatial data usage and capacity building.

Some of the studies countries share a common cartographic history since recently (like the former Yugoslavian Republics of Bosnia and Herzegovina, Croatia, FYROM, Slovenia, Montenegro and Serbia) or even in the past (era of the AustroHungarian Monarchy) they were once part of a common country. There still exist small scale maps and even large scale and cadastral maps from those times. However, the development of the national spatial data infrastructure took different ways in those countries, and as the consequence the national data sets are hardly useful at the trans-national levels (different data sharing policy, quality standards, spatial reference systems etc.). Among the countries, only Greece, Bulgaria and Slovenia are the EU member, obliged to follow the EU directives also in the fields of SDI. The countries participate in several international initiatives and projects dedicated to technological and general development in these fields (Table 1).

\begin{tabular}{|l|c|c|c|c|c|}
\hline Country & ESA & EuroSDR & GEO & ISPRS & $\begin{array}{c}\text { EuroGeo } \\
\text { graphics }\end{array}$ \\
\hline Albania & - & - & - & - & $\mathrm{P}$ \\
\hline BiH & - & - & - & - & $\mathrm{P}$ \\
\hline Bulgaria & - & - & $\mathrm{P}$ & - & $\mathrm{P}$ \\
\hline Croatia & - & $\mathrm{P}$ & $\mathrm{P}$ & $\mathrm{P}$ & $\mathrm{P}$ \\
\hline FYRoM & - & - & - & - & $\mathrm{P}$ \\
\hline Greece & $\mathrm{P}$ & - & $\mathrm{P}$ & $\mathrm{P}$ & $\mathrm{P}$ \\
\hline Serbia & - & - & $\mathrm{P}$ & - & $\mathrm{P}$ \\
\hline Slovenia & $\mathrm{C}$ & - & $\mathrm{P}$ & $\mathrm{P}$ & $\mathrm{P}$ \\
\hline Turkey & - & - & $\mathrm{P}$ & $\mathrm{P}$ & $\mathrm{P}$ \\
\hline
\end{tabular}

Table 1. Participation in international organizations ( $\mathrm{P}-$ participating; c - cooperating)
A survey among the national stakeholders performed as part of the OBSERVE (Observe, 2012) and BalkanGEONet (BalkanGEONet, 2012) projects showed the problem of poor coordination of data providers, incompatible data formats and the lack of data quality. In spite of a variety of activities there is a lack of coordination in data provision and sharing, for which coordination at the national level is needed, where governmental bodies have to play a leading role through intersectorial cooperation (Observe, 2012).

\section{HIGHER EDUCATION IN THE BALKAN AREA RELATING TO EO}

For many years every country just followed its own way in professional training and education in the fields of SDI and EO. In the most Balkan countries, the curricula relating to the Earth Observation activities have been developed in the framework of the higher education programmes of geodesy and surveying which is a common phenomenon throughout Europe (see Lisec and Ruiz Fernández, 2008). Geodesy was traditionally developed in order to understand natural phenomena which are related to the size, shape, gravity field of the Earth. Terrestrial surveys and geodetic measurements have been the fundaments for determining size and shape of the Earth and position of spatial phenomena. On the other hand, the history of surveying goes back to the time when man settled permanently the land. The importance of this crucial natural resource forced the human to develop technical and methodological solution for land evidences and protection of rights on land. As the consequence, the surveying courses and EO relating courses are nowadays included also in the study programs of agriculture and forestry (Bulgaria, Croatia, Greece, Slovenia), and mining and geology (Bulgaria). Furthermore, surveying and geodesy provided the basis for mapping. This is the main reason why the EO courses are often included also in the study programmes of geography (Bulgaria, Croatia, Slovenia). Table 1 summarizes information on dedicated undergraduate and graduate study programs relating to EO in the selected countries (Data Source: Observe, 2012).

\begin{tabular}{|c|c|c|c|}
\hline Country & $\begin{array}{c}\text { No of } \\
\text { faculties/ } \\
\text { institutes }\end{array}$ & $\begin{array}{c}\text { No of } \\
\text { graduate } \\
\text { programs }\end{array}$ & $\begin{array}{l}\text { Study period } \\
\text { (years) }\end{array}$ \\
\hline Albania & 2 & 1 & $4-5$ \\
\hline $\mathrm{BiH}$ & 2 & 2 & $4-5$ \\
\hline Bulgaria & 8 & 8 & $\begin{array}{l}3 \text { (undergrad.) } \\
5 \text { (graduate) }\end{array}$ \\
\hline Croatia & 3 & 3 & 5 \\
\hline FYRoM & 1 & - & 3 (undergrad.) \\
\hline Greece & 4 & 2 & $\begin{array}{l}4 \text { (undergrad.) } \\
5 \text { (graduate) }\end{array}$ \\
\hline Serbia & 3 & 3 & 5 \\
\hline Slovenia & 4 & 4 & $\begin{array}{c}5 \\
(3(\mathrm{BSc})+2(\mathrm{MSc}))\end{array}$ \\
\hline Turkey & 18 & 14 & 4 \\
\hline
\end{tabular}

Table 2. Dedicated undergraduate and graduate programs relating to EO

In Albania, there are 3 main public universities and to be considered with reserve some private universities. New study programs according to Bologna program are being implementing since 2004. There are 4 research institutions concerning EO activities in the country. 
In Bosnia and Herzegovina, there are 28 universities and colleagues in the country, only two of them have courses relating to the EO. New study programs according to Bologna program are being implementing, $\mathrm{BA} / \mathrm{BSc}$ generally started in the academic year 2005/2006. There is only one research institute concerning $\mathrm{EO}$ activities in the country.

In Bulgaria, there are 4 universities and 15 colleagues; 8 of them are issuing degrees in geodesy, photogrammetry, remote sensing, LIS/GIS, geomatics. There are 6 academic scientific institutes concerning EO activities in the country.

In Croatia, there are 6 universities and 5 colleagues in the country. New study programs according to Bologna program are being implementing, first BA/BSc started in the academic year 2005/2006. The EO courses are mainly included in the study programmes of geodesy, agronomy and forestry. There are 5 research institutes concerning EO activities in the country.

In Former Yugoslav Republic of Macedonia, there are 6 universities and colleagues in the country. New study programs according to Bologna program are being implementing, each of these universities within some study program teaches about EO but there is no particular graduate course on surveying and geoinformatics (currently only undergraduate course). Based on Observe research, not even a single EO data producer of provider performs scientific research and only two are using results from scientific research in their work.

In Greece, there are 2 universities and 2 professional educational institutes in the country strictly dedicated to geomatics that are responsible for the field of Spatial and EO data. Several other universities and higher professional technical schools are introducing EO courses in the framework of different study programs, such as geology, agriculture, forestry, marine science. There are no dedicated Research Institutes concerning EO activities in the country.

In Serbia, there are 7 state-owned universities in the country. New study programs according to Bologna program are being implementing, first $\mathrm{BA} / \mathrm{BSc}$ started in the academic year 2006/2007. There are two university and one higher professional study program relating to surveying and geomatics. Serbia has 1 research institute concerning EO activities in the country.

In Slovenia, there are 5 universities and 18 colleagues in the country. New study programs according to Bologna program have been implemented, first BA/BSc started in the academic year $2008 / 2009$. The surveying and geomatic study program is organized only at one university, while different study programs, such as geography, agronomy, geology and forestry also have courses relating to EO. There are 3 research institutes concerning EO activities in the country.

In Turkey, there are 18 universities in the country, all of them have at least undergraduate study program relating to surveying or EO. New study programs according to Bologna program are on the process. There are 9 research institutes concerning EO activities in the country.

The complexity of contemporary higher education in the fields related to the spatial data and EO demands that the new, narrow oriented modern technology is introduced. Regular reforms of higher educational programmes attempt to adjust curricula to the new conditions of science and society. The nature of EO- profession, including surveying, geodesy and geoinformatics, is changing and new areas are developing very rapidly. New technologies and the extension of the field of the profession require new concepts and structures in education. Based on the research activities in the selected countries and our experiences as guest lecturers in some of the Balkan countries, it has to be emphasized, that there is a huge difference among the countries relating to the basic (technological) infrastructure for introducing the advanced technology to students. The main reason is that the expensive equipment, software, database etc. are not available at all universities (see also Lisec and Kosmatin Fras, 2008). The need for education in specific areas demands cooperation between the educational institutions in the area.

The new technologies and methodologies are inevitably entering also the everyday practice. For this reason, the cooperation between academia, professional enterprises and public institutions has to be supported, as well as trans-national research and applicative projects.

\section{CONCLUSIONS}

Technology continues to draw the nations of the world closer together. Due to the need for the cross-border cooperation in several decision problems relating to the environment and space in general (for example disaster management, climate change policies), the need for a common platform for spatial decision making is evident also in the Balkan region. For this purpose, the capacity building is an important issue, which has not be overlooked or seen to narrow - the capacity refers to the ability of individuals and organizations to make and implement decisions and perform functions in an effective, efficient and sustainable manner. Here, the official educational programs, including the higher educational programs, are of high importance.

Furthermore, the Earth Observation activities might be a unique tool for the understanding of the Earth's system and its processes, which can be a valid support to school and university teaching in subjects such as geography, physics and Earth science. For these reasons, the EO courses might be introduced in different study programs. Monitoring our planet and its environment, detecting and understanding its variations is more and more important, in the planet threatened by global change and climate change, where the uncontrolled use of natural resources like biomass, carbon and clean water associated to the explosion of demography could make life conditions of future generations hard. The observation of the changing Earth from space can provide a valid support to the creation of public awareness, support decision makers and politicians, as well as for the education of young generations.

\section{REFERENCES}

BalkanGEONet, 2012. Strengthening and development of Earth Observation activities for the environment in the Balkan area. The project documentation.

http://www.balkangeo.net/ (20 Mar. 2012).

European Parliament and Council, 2007. Directive 2007/2/EC of the European Parliament and of the Council of establishing an Infrastructure for Spatial Information in the European Community (INSPIRE).

http://inspire.jrc.ec.europa.eu (20 Mar. 2012). 
Georgiadou, Y., Groot, R., 2002. Capacity building for geoinformation provision: A public goods perspective. $6^{\text {th }}$ Seminar on GIS and Developing Countries, Enschede, May 15-18, 2002.

GINIE, 2003. GI Capacity Building in the EU Accession Period: Technical Report D 3.8 .2 (b). University of Sheffield in cooperation with EUROGI, JRC and OGCE.

Higher Education in Europe, 2033. The External Dimension of the Bologna Process: Higher Education in SEE and the EHEA in a Global World, 28(3).

Kufoniyi, O., Huurneman, G., Horn, J., 2005. Human and Insitutional Capacity Building in Geoinformatics Through Educational Networking. In: FIG Working Week 2005 and GSDI-8, Cairo, April 16-21, 2005.

Lisec, A., Kosmatin Fras, M., 2008. Supplementary Short-term Education for Students as Stimulation to Scientific and Research Work. In: Luis Ángel Ruiz Fernández (ed.), Jerzy Chmiel (ed.). Proceedings of the 2007 International Congress on Geomatics Education in Europe, Warsaw, Poland. Valencia, Spain. ISBN: 978-84-8363-226-0: 80-91.

Lisec, A., Ruiz Fernández, L. Á., 2008. European project on higher education in the fields related to Geomatics as support for mobility of students and teachers. In: The International Archives of the Photogrammetry, Remote Sensing and Spatial Information Sciences, Beijing, China, Vol. XXXVII, Part B6a, pp. 185-190.

Observe, 2012. Strengthening and development of Earth Observation activities for the environment in the Balkan area. The project documentation.

http://www.observe-fp7.eu/ (20 Mar. 2012).

Sandler, T., 1998. Global and regional public goods: A prognosis for collective action. Fiscal Studies, 19(3), pp. 221247.

The Bologna Declaration, 1999. Joint declaration of the European Ministers of Education, June 19, 1999.

Zgaga, P. 2011. The role of higher education in national development: South-Eastern Europe and Reconstruction of Western Balkans. The Europa World of Learning 2011. Routledge. ISBN 978-1-85743-567-2.

\section{ACKNOWLEDGEMENTS}

The research leading to these results has received funding from the European union's Seventh Framework Programme under grant agreement No 265282. 